\title{
Reptilian diving: highly variable dive patterns in the green turtle Chelonia mydas
}

\author{
S. Hochscheid ${ }^{1, *}$, B. J. Godley ${ }^{2}$, A. C. Broderick ${ }^{2}$, R. P. Wilson' ${ }^{1}$ \\ 'Institut für Meereskunde, Düsternbrooker Weg 20, D-24105 Kiel, Germany \\ ${ }^{2}$ Marine Turtle Research Group, School of Biological Sciences, University of Wales Swansea, Singleton Park, \\ Swansea SA2 8PP, United Kingdom
}

\begin{abstract}
Diving reptiles, unlike most diving birds and mammals, return infrequently to the surface to breathe. Spending the bulk of their lives underwater, they are likely to have developed a large variety of specific behavioural patterns different from those of their warm-blooded counterparts. However, for technical reasons, underwater behaviour of these aquatic reptiles remains poorly understood. In this study green turtles Chelonia mydas nesting on Cyprus (Eastern Mediterranean) were equipped with multi-channel data loggers monitoring diving behaviour and activity (via a logger-integrated 3-D compass which served as an activity sensor) during the inter-nesting interval. Data from 2 turtles for 2 consecutive inter-nesting intervals were available for detailed dive analysis. Both turtles showed highly variable dive patterns ranging from travelling subsurface dives to specific dive types such as U- (mainly resting and foraging dives), S- (a form of energy saving swimming) and V-dives. The green turtles stayed near the coast throughout the study, dived no deeper than ca $25 \mathrm{~m}$, but remained underwater for up to ca $40 \mathrm{~min}$. The recordings of the activity sensor revealed high activity levels (less than $20 \%$ resting $\mathrm{d}^{-1}$ ) during the whole inter-nesting period which was attributed to extensive foraging. The combination of both the activity data and the dive data showed that the turtles were engaged in travelling movements for $46 \%$ of the inter-nesting time spent underwater, foraged for $34 \%$ and rested for $12 \%$ of the time. We discuss the physiological, ecological and conservation implications of these results
\end{abstract}

KEY WORDS: Sea turtles - Wildlife telemetry - Underwater activity · Dive profiles · Mediterranean

\section{INTRODUCTION}

Air-breathing aquatic animals are only secondarily adapted to life underwater. One of the main factors limiting time and activities underwater is oxygen supply, specifically the extent of $\mathrm{O}_{2}$ stores and the rate at which they are used up (Butler \& Jones 1997). In addition, any examination of time activity budgets of airbreathing aquatic animals must consider the rate at which $\mathrm{O}_{2}$ supplies are replenished, the time at the surface being, in part, dedicated to this (Kramer 1988). Consideration of the relative amounts of time used by air-breathing marine animals allocated to surface and subsurface living has led to the postulation of 2 cate-

\footnotetext{
- Present address: Department of Zoology, University of Aberdeen, Tillydrone Avenue, Aberdeen AB24 2TZ, Scotland, United Kingdom. E-mail: s.hochscheid@abdn.ac.uk
}

gories: 'divers' (those animals which spend most of their time on the surface, dives occur in bouts when the animal forages) and 'surfacers' (those animals which spend most of their time at sea underwater, surfacing only briefly for gas exchange; Kramer 1988, Kooyman 1989). Turtles are surfacers; they can stay underwater for particularly extended periods due to their slow reptilian metabolism and their extreme resistance to asphyxial distress (Berkson 1966). Therefore these animals can be engaged in a variety of underwater activities which are only interrupted by short surfacing events in order to regulate gas balance.

Recent telemetric studies on sea turtles have given insight into various dive patterns which can widely differ among species regarding parameters such as dive depth and dive duration. For example, leatherback turtles Dermochelys coriacea regularly descend to greater than $100 \mathrm{~m}$ depth (with maximum dive depths 
$>1000 m_{i}$ Eckert et al. 1986, 1989). Similar depth utilisation has been reported for loggerhead turtles Caretta caretta (Naito et al. 1990, Sakamoto et al. 1990). In contrast to this rather pelagic dive behaviour, adult green turtles Chelonia mydas (Carr et al. 1974, Mortimer \& Portier 1989, Liew \& Chan 1992), hawksbill turtles Eretmochelys imbricata (juvenile turtles: Van Dam \& Diez 1996, inter-nesting female turtles: Storch et al. in press) and Kemp's ridley Lepidochelys kempi (Mendonca \& Pritchard 1986, cited in Lutz \& Musick 1997) have been shown to stay in shallow waters and to have a more neritic lifestyle (sensu Hendrickson 1980). Although a number of dive profiles for marine turtles have been presented, none of these studies discussed individual dive types as a function of underwater activity. Thus, we equipped green turtles nesting in the Eastern Mediterranean with multi-channel data loggers (DK600) which measured 5 parameters at a constant sampling interval. As nothing is known about the inter-nesting behaviour of green turtles at northern Cyprus we were especially interested in the variety of dive patterns that they performed. Moreover we wanted to determine the activities in which these turtles were engaged during their inter-nesting period and whether these activities could be assigned to specific dive patterns.

\section{MATERIALS AND METHODS}

The study was conducted in 1997 at Alagadi, northern Cyprus $\left(35^{\circ} 21^{\prime} \mathrm{N}, 33^{\circ} 30^{\prime} \mathrm{E}\right)$, where green turtles Chelonia mydas nest annually (Broderick \& Godley 1996). To elucidate the diving behaviour during the inter-nesting period 4 female green turtles (Turtles 1 to 4) were equipped with DK600 data loggers (Driesen \& Kern GmbH, Bad Bramstedt, Germany). The devices have 6 recording channels which can record up to a maximum of $2 \mathrm{MB}$ of data with 16-bit resolution for each channel. The start can be programmed to be delayed up to $24 \mathrm{~h}$ and the sampling interval is userspecified between $2 \mathrm{~s}$ and $24 \mathrm{~h}$. For this study the sampling interval was set at $15 \mathrm{~s}$ to cover a $4 \mathrm{wk}$ period (e.g. 2 inter-nesting periods) so that the logger would record a second inter-nesting period if the turtle were not recovered during its following nest attempt. Each unit was equipped with: (1) a temperature sensor that measured ambient temperature via a platinum resistance $\left(100 \Omega=0^{\circ} \mathrm{C}\right)$ with an accuracy of $0.05^{\circ} \mathrm{C}$ for temperatures between $-40^{\circ} \mathrm{C}$ and $80^{\circ} \mathrm{C}$; (2) a light sensor measuring light intensity between ca 0.1 and ca 10000 lux; (3) a swim speed sensor, based on measurements of differential pressure using a Prandtl tube (range 0 to $20 \mathrm{~m}$ $\mathrm{s}^{-1}$, accuracy $0.1 \mathrm{~m} \mathrm{~s}^{-1}$ ); (4) a depth gauge that recorded the absolute pressure up to a maximum depth of $100 \mathrm{~m}$ with a resolution of $0.1 \mathrm{~m}$; and (5) a 3-D compass system, containing 2 Hall-sensors (1 channel for each) which recorded the heading and pitch angle of the studied turtle. Additional details of this compass system are given in Hochscheid \& Wilson (1999, in this issue) The loggers were powered by a $3.6 \mathrm{~V}$ Lithium battery and encased in a hydrodynamically shaped epoxy housing. The units weighed ca $200 \mathrm{~g}$ and had maximum dimensions of $147 \times 65 \times 30 \mathrm{~mm}$.

To bring the logger in line with the shape of the carapace it was attached to the second central scute to minimise drag (cf. Bannasch et al. 1994) and optimise measurement of speed and light. Before attachment, the shell was cleaned with acetone and sanded to increase the bonding area for the adhesive. Initially, the logger was held in position by velcro glued to both the underside of the data logger and to the carapace. Three wires (diameter: $2.5 \mathrm{~mm}$, length: ca $350 \mathrm{~mm}$ ) were then bent over the logger and covered with epoxy resin on both sides of the device. The total duration of the attachment process was approximately $10 \mathrm{~min}$ and was undertaken while turtles laid their clutch.

Recovery of data loggers was facilitated by nightly patrols of the nesting beaches by 3 to 4 groups of volunteers recording every turtle activity. Because of the intensive survey effort every nesting green turtle was observed. Removal of the devices was only undertaken when the female had started to lay eggs and care was taken to ensure that all resin was removed. Although a total of 4 turtles was equipped, 2 turtles (Turtles 1 and 2) were equipped for 2 separate, successive inter-nesting periods. The device removed after the first internesting period was replaced by a second device to monitor behaviour over a second inter-nesting period.

Dive parameters were analysed using the program V3 (Jensen Software Systems, Laboe, Germany). This program assesses the dive depth data and calculates the time at which each dive occurred, as well as some 40 parameters for each dive. The parameters considered for further analysis in this study were: total dive duration, descent duration, bottom duration, ascent duration, number of dive stops (a phase during ascent where the turtle remained at a specific depth for at least 15 s, i.e. 1 recording interval bounded by 2 measurements in the same depth), duration of each dive stop and the depth at which a dive stop began. We considered all dives which exceeded a depth of $2.5 \mathrm{~m}$ as discrete dives. Shallower dives could only be poorly assessed due to the rather coarse sampling interval (Wilson et al. 1995). All dives quantified by V3 were displayed on the computer screen for visualisation by the program user before being stored on file for further analysis.

The activity during the inter-nesting period and during particular diving events was determined using an 
activity index (AI) as described in Hochscheid \& Wilson (1999). This method was based on the 3-D compass system of the logger which served as an activity sensor by measuring the change in turtle orientation, something that is always associated with movement. The AI (in relative units) gave information about the state of the turtle; thus it was possible to distinguish clearly between movement (typical values for swimming ranged between 68 and $100 \%$ of maximum AI) and resting $(<2 \%$ of the maximum $\mathrm{AI})$.

For the determination of daily activity patterns days were split into 4 phases: night (duration ca $8 \mathrm{~h}$ ), sunrise (ca $1.5 \mathrm{~h}$ ), day (ca $12 \mathrm{~h}$ ) and sunset (ca $1.5 \mathrm{~h}$; these are all approximate values which therefore do not add up to exactly $24 \mathrm{~h}$ ). The beginning and end of each day phase were set using typical values of light intensity, taking into account the geographical position of Alagadi as recorded by the logger (the individual light sensors had been calibrated on site prior to deployment). Sunrise was taken to be the period between sun angles of $-12^{\circ}$ and $0^{\circ}$ and sunset between $0^{\circ}$ and $-12^{\circ}$. Day and night were considered to occur between sunrise and sunset.

\section{RESULTS}

Five of the six data loggers deployed were recovered. These recorded data during 2 of the inter-nesting intervals of each of Turtle 1 (Loggers 1.1 and 1.2) and Turtle 2 (Loggers 2.1 and 2.2) and from 1 inter-nesting interval of Turtle 3 (Logger 3.1). Although Turtle 4 was re-sighted at the study site after approximately 1 internesting interval, it did not re-nest and the logger was not recovered. It is likely that it nested at another nearby nesting beach. The attachment/detachment procedures appeared to have no effect on the turtles nesting behaviour. Each nesting event was completed. Data recording was confounded by several technical problems: (1) All data loggers were physically damaged by mating activities or abrasion with underwater rocks. The protruding speed vane had been damaged in all cases, which led to a failure in the measurement of speed after a maximum of $2.5 \mathrm{~d}$. (2) Data logger 1.2 was stopped recording after Day 5 due to the intrusion of water into the battery case. (3) It is likely that low battery voltage caused failure to record in Logger 1.1 after $10 \mathrm{~d}$, Logger 2.1 after $11 \mathrm{~d}$, and Logger 3.1 after $1 \mathrm{~d}$. Data were obtained for the complete inter-nesting period (12 d) by Logger 2.2. (4) In 3 data sets $(1.1,1.2$ and 2.1) there were inconsistencies in the depth measurement during periods of high light intensity due to a light-dependent output of the pressure sensor. This was due to the fact that we had, in most cases, reduced the size of the chimney leading from the exterior to the
Table 1. Maximum dive depth (MDD) and total dive duration (TDD) of 2 successive inter-nesting periods (INP) of Turtles 1 and 2. Median and first and third quartiles (Q1 and Q3) are given. $n=$ number of dives analysed

\begin{tabular}{|lrrrr|}
\hline & \multicolumn{2}{c}{ Turtle 1 } & \multicolumn{2}{c|}{ Turtle 2 } \\
\multicolumn{1}{c}{ INP: } & 1.1 & 1.2 & 2.1 & \multicolumn{1}{c}{2.2} \\
\hline MDD (m) median & 6.2 & 7.8 & 4.4 & 5.4 \\
Q1 & 4.8 & 5.9 & 3.6 & 3.9 \\
Q3 & 7.6 & 9.2 & 6.5 & 8.7 \\
TDD (min) median & 8.25 & 10.0 & 7.0 & 11.0 \\
Q1 & 3.25 & 3.75 & 3.5 & 5.8 \\
Q3 & 14.25 & 18.5 & 11.75 & 15.8 \\
n & 523 & 274 & 617 & 871 \\
\hline
\end{tabular}

depth transducer for streamlining purposes (cf. Bannasch et al. 1994, Watson \& Granger 1998). We subsequently discovered that the transducer was light sensitive so that the extreme values of light intensity in the study area led to unreliable depth measurements during the day. For this reason daytime dive profiles of 3 data sets were not identifiable and were discarded.

Notwithstanding, dive patterns and underwater activity could by analysed for a total of 2285 dives performed by 2 individuals during 2 consecutive internesting intervals, with maximum recorded dive depth of $24.8 \mathrm{~m}$ and a maximum dive duration of $40 \mathrm{~min}$. Individual turtles showed no striking differences in dive duration or dive depth (Table 1).

\section{Different dive types}

For the analysis of dive types we worked with depth data randomly selected from $5 \mathrm{~d}$ of each inter-nesting period (this value being equivalent to the shortest data set from Turtle 1). Both turtles showed a variety of different dive patterns (Fig. 1). We distinguished 4 main dive types: (1) U-dives, which were characterised by a steady descent (calculated mean vertical velocity $V_{\mathrm{v}}=$ $0.16 \mathrm{~m} \mathrm{~s}^{-1}, \mathrm{SD}=0.07, \mathrm{n}=470$ ) followed by extended time spent at a constant depth (bottom time) followed by a steady ascent (mean $V_{\mathrm{v}}=0.14 \mathrm{~m} \mathrm{~s}^{-1}, \mathrm{SD}=0.07, \mathrm{n}$ = 470; cf. Le Boeuf et al. 1988); (2) V-dives, which had a steady descent (mean $V_{\mathrm{v}}=0.08 \mathrm{~m} \mathrm{~s}^{-1}, \mathrm{SD}=0.05, \mathrm{n}=$ 123) and ascent phase (mean $V_{\mathrm{v}}=0.06 \mathrm{~m} \mathrm{~s}^{-1}, \mathrm{SD}=$ $0.04, \mathrm{n}=123$ ) but no bottom time; (3) subsurface dives (SSD), which refer to those phases when the turtle was swimming in the upper $2.5 \mathrm{~m}$ layer (a specific dive profile could not be resolved due to over-long measurement intervals (see earlier); and (4) S-dives, which we name so because of the S-shaped ascent in the dive profile (Fig. 1). This dive type could be divided into 4 phases following suggestions by Graham et al. (1987) 
time $[\mathrm{h}: \mathrm{mm}]$
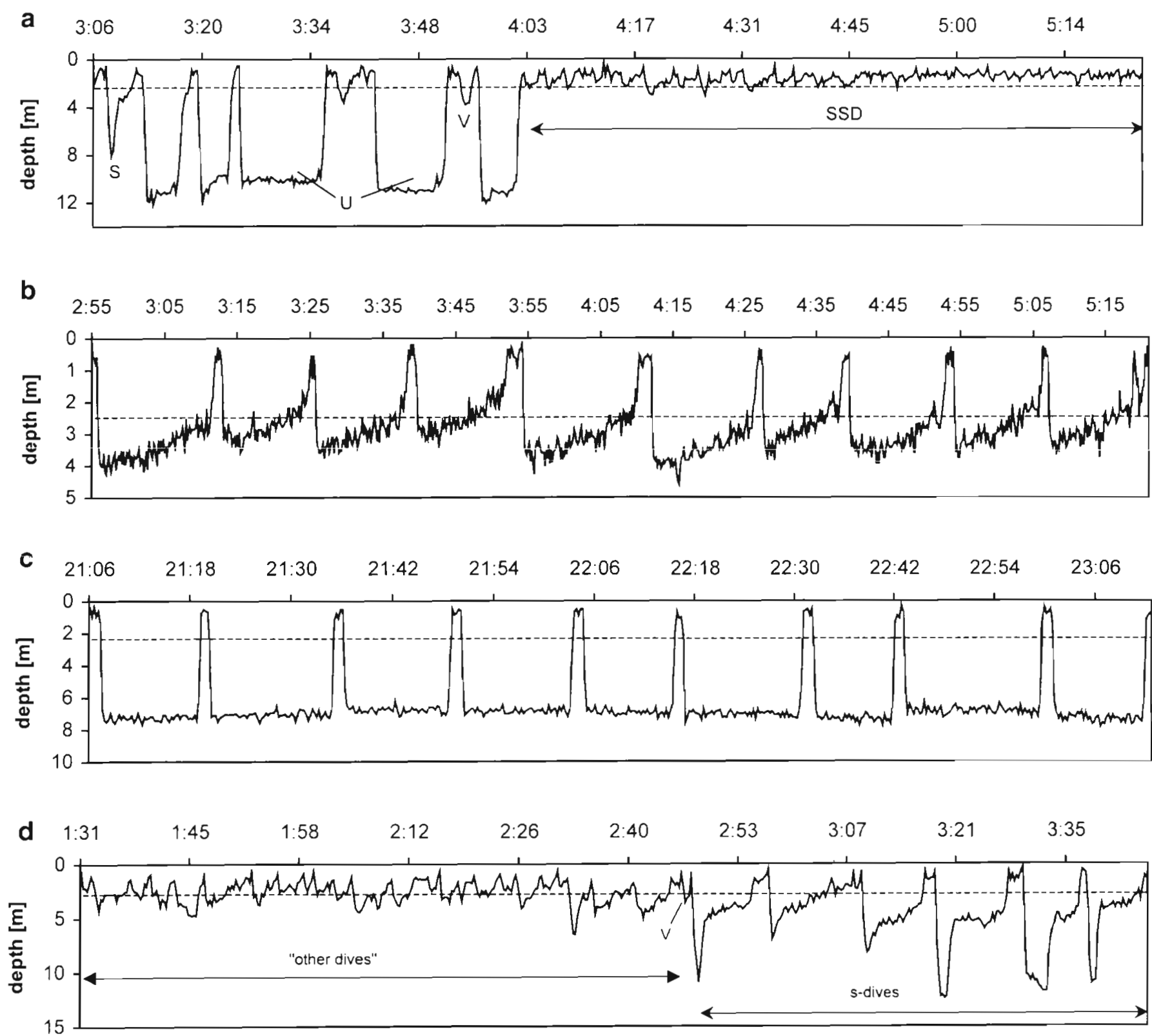

Fig. 1. Typical dive profiles from 2 green turtles: (a) discrete dives ( $S=S$-dive, $U=U$-dive, $V=V$-dive) followed by a period of subsurface dives (SSD), (b) a series of shallow travelling dives, (c) a series of U-dives, (d) S-dives and 'other dives' (----) Depth at which a dive was considered a discrete dive

delineated by points of inflection in the dive profile: Phase I was a rapid descent to a maximum depth (mean $V_{v}=0.13 \mathrm{~m} \mathrm{~s}^{-1}, \mathrm{SD}=0.06, \mathrm{n}=68$ ); Phase II immediately followed Phase I and was an ascent to a specific depth (mean $V_{\mathrm{v}}=0.07 \mathrm{~m} \mathrm{~s}^{-1}, \mathrm{SD}=0.05, \mathrm{n}=$ 68); Phase III consisted of a very slow ascent over extended time (mean $V_{\mathrm{v}}=0.03 \mathrm{~m} \mathrm{~s}^{-1}, \mathrm{SD}=0.03, \mathrm{n}=$ 40). This was followed by Phase IV where the turtle finally rose to the surface (mean $V_{\mathrm{v}}=0.02 \mathrm{~m} \mathrm{~s}^{-1}, \mathrm{SD}=$
$0.001, \mathrm{n}=41$ ). Sometimes the point of inflection between Phases III and IV was not well developed, so that Phase III seemed to be continued right to the surface. In the following we will refer to Phase III as a 'dive stop'.

Of the time spent underwater U-dives accounted for the largest proportion (46\%). SSD accounted for $35 \%$ of the time, and S-dives for $11 \%$, while $\mathrm{V}$-dives only accounted for $2 \%$ of the time spent underwater. A fur- 
ther $6 \%$ of the time was spent engaged in dives of poorly defined form, classified as 'other'.

Using our subsample of dives from $5 \mathrm{~d}$ of each data set, we then compared the maximum dive depth (MDD) with the total dive duration (TDD) for $\mathrm{U}_{-}, \mathrm{S}$ - and $\mathrm{V}$-dives. In all different dive types these parameters were significantly correlated $(\mathrm{p}<0.001$; U-dives: $F=$ 214.9, $\mathrm{n}=470$; S-dives: $F=19.94, \mathrm{n}=186$; $V$-dives: $F=$ $26, n=123$ ), although there were substantial differences between dive types in best curve fits for this relationship (Fig. 2). V-dives were usually the shortest in duration, followed by S-dives, which were in turn shorter than the U-dives. Whereas the total dive duration of S-and V-dives correlated linearly with the maximum dive depth in the depth range utilised by the studied turtles, a logarithmic description of time/depth utilisation during $\mathrm{U}$-dives was more appropriate (Udives: $r=0.595, n=470$; S-dives: $r=0.3127, n=186 ; \mathrm{V}$ dives: $r=0.432, n=123$ ).

\section{Characteristics of U-dives}

Due to the importance of $U$-dives in the time budget of green turtles we studied AIs (see 'Materials and methods') during these dives to determine whether all U-dives performed the same function or whether they were characterised by different bottom activities. Comparisons of AIs with dive profiles indicated that not every $U$-dive functioned as a resting dive but rather that the turtles were not always stationary (Fig. 3). The frequency distribution of AIs determined from 200 randomly selected U-dives was bimodal (Fig. 4). Of the dives $25.3 \%$ (2 columns ' $81-90$ ' and ' $91-100$ ' in Fig. 4) were mainly resting dives while during $30.3 \%$ of the dives ( 2 columns ' $0-10$ ' and ' $11-20$ ' in Fig. 4) turtles were active for $>80 \%$ of the dive and in $12 \%$ of all U-dives turtles were active for the complete dive. In $44.3 \%$ of the U-dives (the 6 remaining columns in the middle of Fig. 4) the turtles were only active part of the time.

\section{Characteristics of S-dives}

The calculated vertical velocity during ascent ( $\left.V_{v} u p\right)$ of S-dives was significantly higher than the vertical velocity during descent ( $V_{\mathrm{v}}$ down; $\mathrm{p}<0.0001, F=95.7$, 1 -way ANOVA). There was a clear decrease in $V_{\mathrm{v}} \mathrm{up}$ during Phase III, which accounted for a mean of $45.2 \%$ ( $\pm \mathrm{SD} 31.8$ to $57.6 \%$ ) of the total dive duration. On average, the duration of the ascent was ca 7 times longer than the duration of the descent. Further analysis of the dive stops revealed a strong correlation between the depth where such a dive stop began and
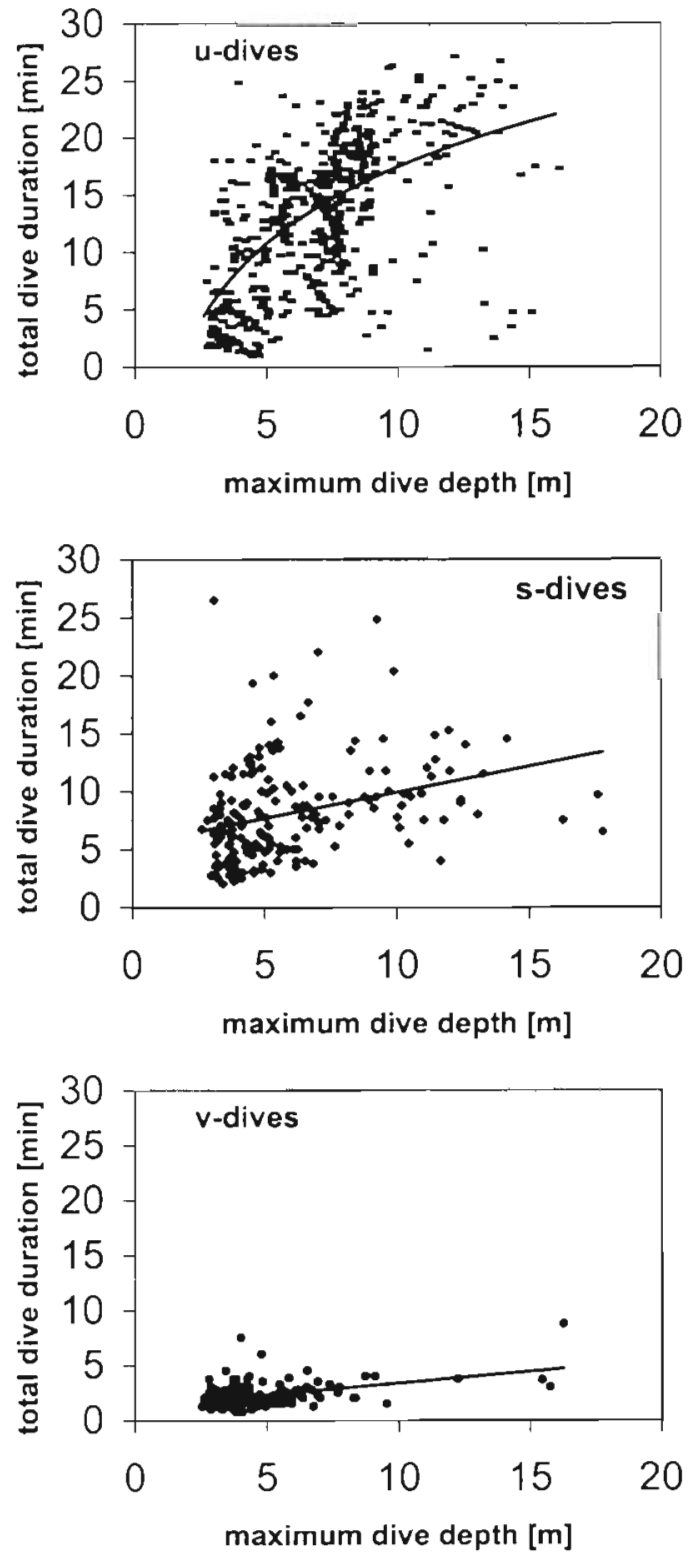

Fig. 2. Correlation between maximum dive depth (MDD) and total dive duration (TDD) for U-dives: $T D D=9.76 \ln (\mathrm{MDD})-$ 5.0239, $\mathrm{r}=0.595, \mathrm{p}<0.001, \mathrm{n}=470 ; \mathrm{S}$-dives: $\mathrm{TDD}=0.4479 \times$ $\mathrm{MDD}+5.407, \mathrm{r}=0.3127, \mathrm{p}<0.001, \mathrm{n}=186$; and $\mathrm{V}$-dives: TDD $=0.21 \times \mathrm{MDD}+1.248, \mathrm{r}=0.423, \mathrm{p}<0.001, \mathrm{n}=123$

the maximum dive depth $(\mathrm{r}=0.8, \mathrm{n}=68, \mathrm{p}<0.001$, Fig. 5a). The duration of the dive stops was also correlated with the maximum dive depth $(r=0.4, n=68, p<$ 0.001) although the values were more scattered (Fig. 5b). Calculation of the AI during the S-dives showed that the turtles remained active throughout the different phases of the dives. A general tendency of an activity decrease was recognisable in Phase III but there was no significant difference between activities in the 4 phases. 


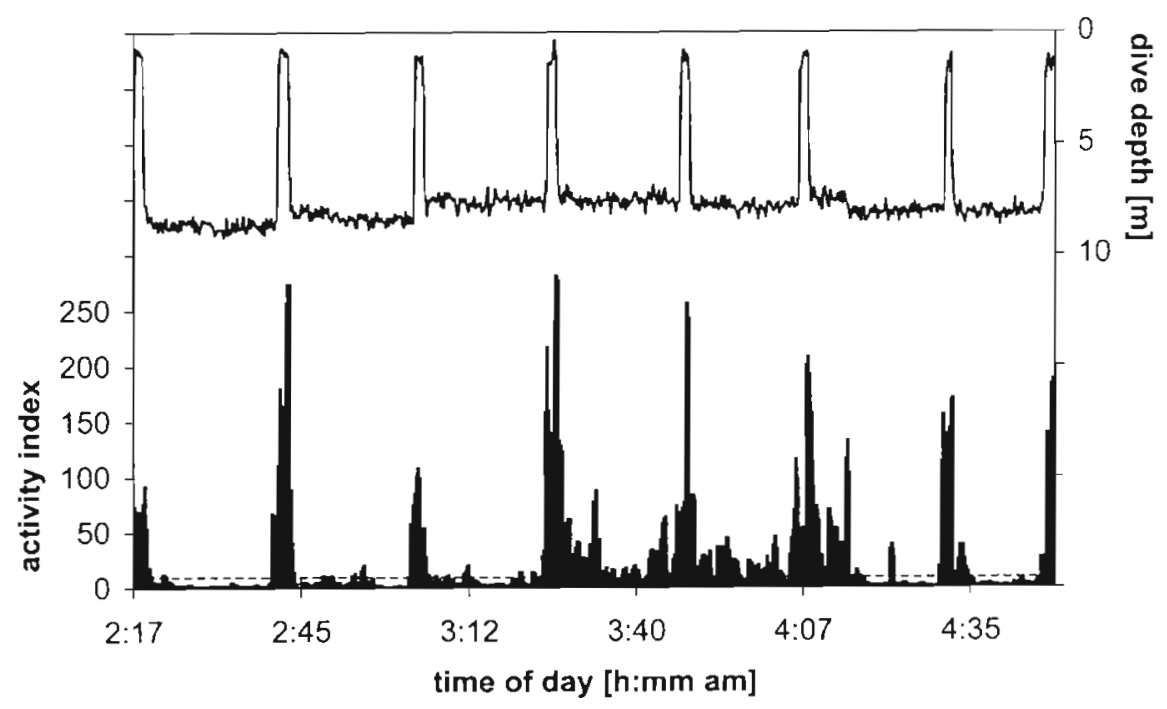

Fig. 3. Caicuiated activity index (AI) (below) for a series of Ú-dives (top). The highest Ais are due to surfacing events. The turtle was resting when the AI was below $2 \%$ of maximum AI (-.---)

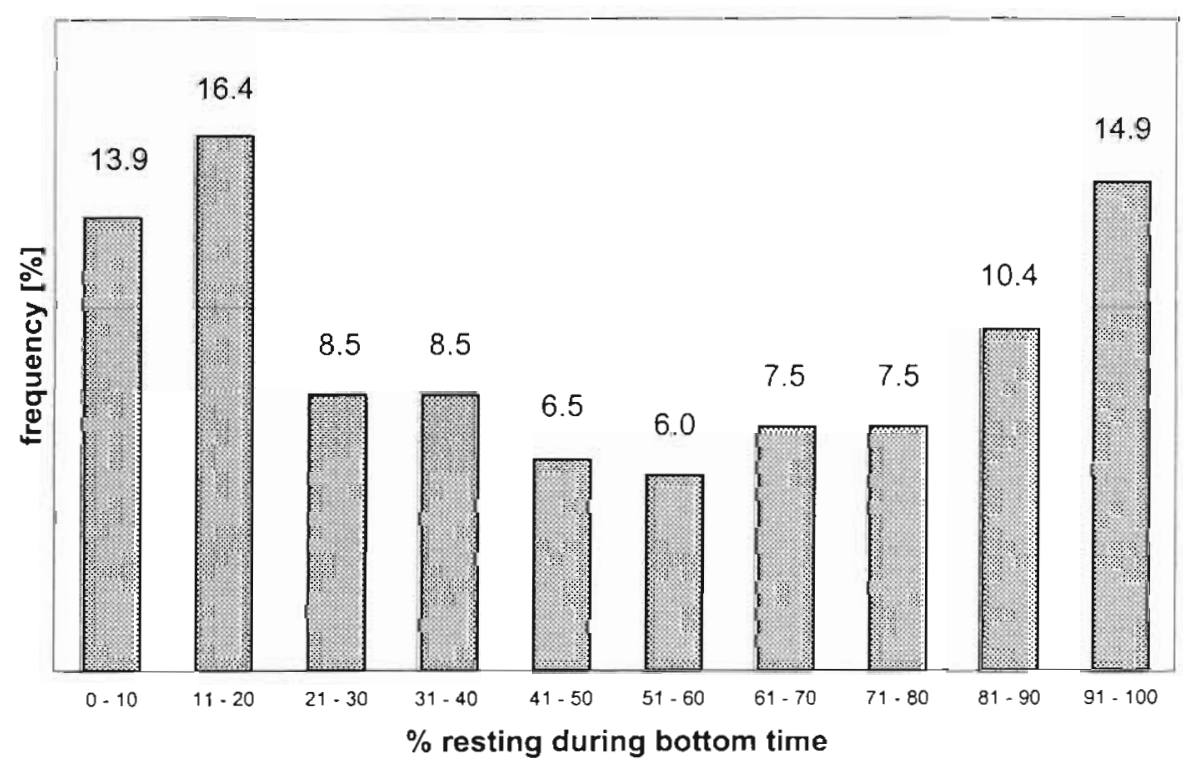

Fig. 4. Proportion of resting during the bottom time of U-dives $(n=200)$

\section{Overall activity during the inter-nesting period}

The overall activity of green turtles during their inter-nesting interval as determined using the AI showed a generally high activity level. On closer examination of activity over the complete inter-nesting interval of Turtle 2 we found that the turtle spent almost no time resting during the first $1.5 \mathrm{~d}$ after nesting. A similar high activity level was maintained during the middle course of the inter-nesting period, this being bounded by 2 short periods ( 1 to $3 \mathrm{~d}$ ) when the turtle spent apparently more time resting (on the sec- ond day after nesting and on the tenth day of the internesting period) (Fig. 6). The difference between those resting periods and the activity period in the middle inter-nesting period is far more striking if the 2 relevant days are extracted for visualisation of the AI over a $24 \mathrm{~h}$ period (Fig. 7). Fig. 7 a clearly shows that the turtle was resting for more than half of the day, the resting being only shortly interrupted by surfacing events. In contrast, on the tenth day the turtle remained active the whole day, resting periods being almost entirely absent (Fig. 7b). Similar observations were made for Turtle 1 . To test whether individual turtles had pre- 
a
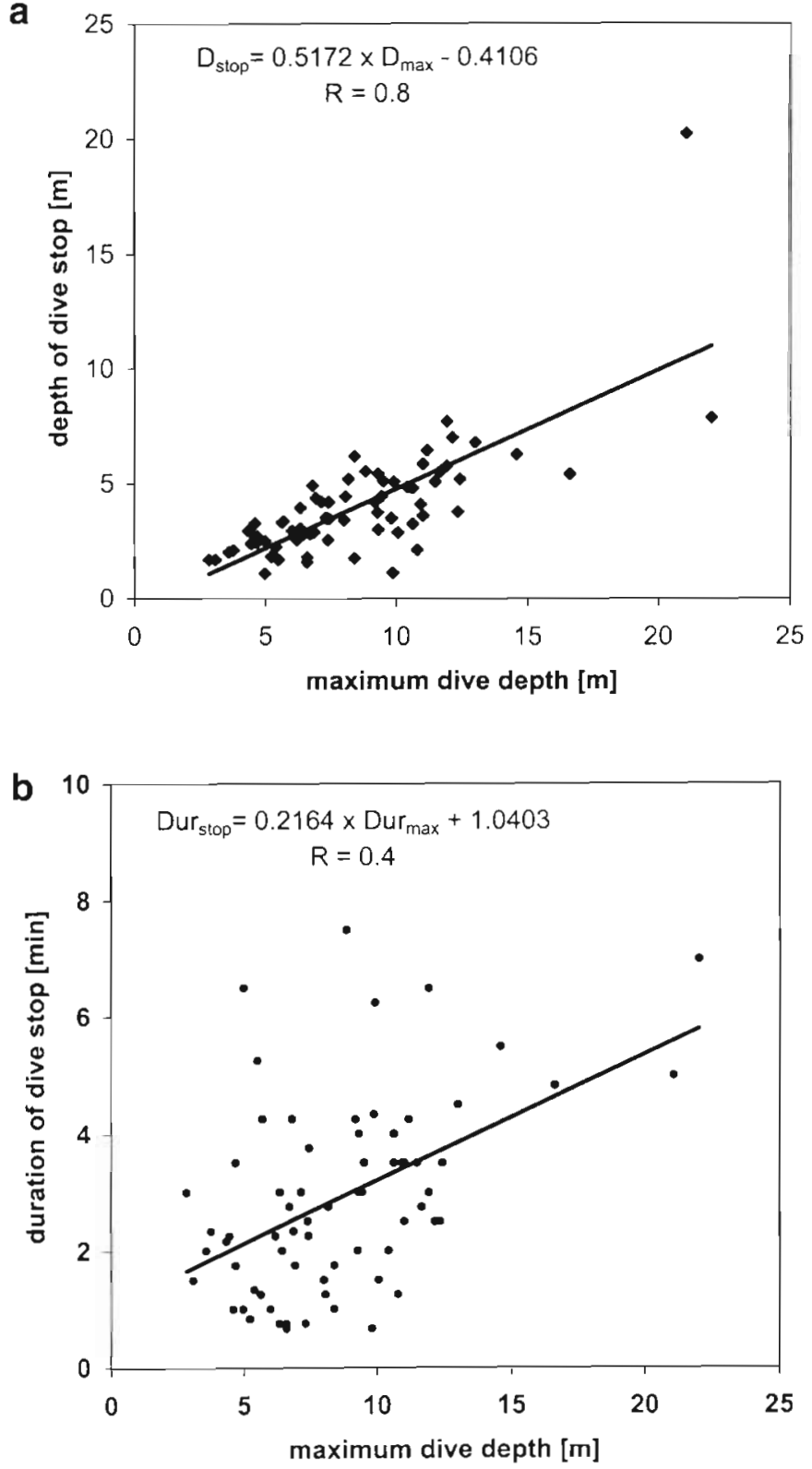

Fig. 5. Dive stops in S-dives: correlation between maximum dive depth and (a) the depth of the dive stop and (b) the duration of the dive stop. $\mathrm{p}<0.001, \mathrm{n}=68$

ferred day times for resting, we compared the proportion of time spent resting during each day phase (night, sunrise, day, sunset; $n=5$ each). No significant differences in resting times were found.

\section{DISCUSSION}

Analysis of dive behaviour in aquatic animals is generally difficult due to the problems of directly observing them in their natural environment. This is espe- cially true for sea turtles, which, in contrast to most other air-breathing aquatic animals, spend the majority of their life submerged. One of the fundamental differences between diving mammals and birds versus diving reptiles is their difference in metabolism. The low rate at which oxygen is used up in reptiles enables these animals to stay underwater for extended periods before returning to the surface for a rapid gas exchange. By analysing particular dive profiles we have shown that the dive behaviour of sea turtles can be far more complex than previously demonstrated. In studies on diving birds and mammals it has been shown that the shape of a dive on a time/depth scale can give information about the activity in which the animal is engaged during the dive (Le Boeuf et al. 1988, Chappell et al. 1993, Wilson et al. 1996, Grémillet et al. 1999). With regard to this, particular dive types have often been characterised and assigned to specific functions such as hunting, searching for prey, travelling, etc. Such detailed dive analysis has rarely been presented for sea turtles. For example, Van Dam \& Diez (1996) distinguish between foraging and resting dives in their study on immature hawksbills (see also Rice et al. in press for sub-adult green turtles). Sakamoto et al. (1990), based on the measurements of a stomach temperature logger in combination with a time depth recorder, even considered some dives to be thermoregulatory in nature. However, simplistic consideration of dive profiles may not be helpful in describing the behaviour of sea turtles because they can be engaged in more than just one activity during the course of a single dive. Further information in addition to time depth recordings is needed to set up a detailed picture of at-sea activities in sea turtles, such as that given by the activity sensor in this study, which enables us to characterise a number of different dive types whose likely function will be discussed here.

\section{Subsurface dives}

SSD showed evidence of high levels of activity in the upper $2.5 \mathrm{~m}$ layer. The dive profiles of SSD clearly show that the turtles did not stay at a constant depth but rather moved quickly up and down as if they were swimming just under the surface. Usually these dives occurred over extended periods of time at the beginning of the inter-nesting period, indicating migratory movements between the nesting beach and an inter-nesting habitat. The relative high activity during the first $1.5 \mathrm{~d}$ also concurs with this. On the basis of the depth utilisation of the turtles we conclude that such an inter-nesting habitat is likely to be a coastal area because the turtles dived no deeper than $25 \mathrm{~m}$. Longer migrations offshore where water 


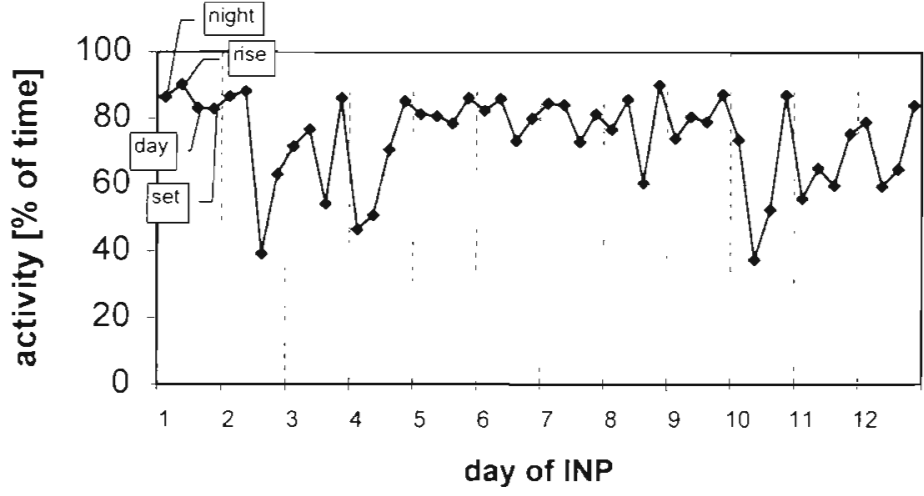

Fig. 6. Activity of Turtle 2 during the second recorded inter-nesting period (INP). Each day (separated by vertical dashed lines) was split in 4 phases: night, sunrise, day and sunset (see 'Materials and methods')

depth usually exceeds $200 \mathrm{~m}$ within $2 \mathrm{~km}$ of the Cyprus coastline are not compatible with the frequent occurrence of resting dives throughout the 4 temporal phases (i.e. night, sunrise, day, sunset). In addition, for energetic reasons it would seem unlikely that turtles would move away from the neritic environment where there are foraging grounds and resting opportunities.
U-dives

U-dives, which were the most abundant dive type, have often been referred to as 'resting dives' meaning that the turtle descends to the sea floor or a solid substratum such as a rocky ledge and stays there for a certain time in an inactive state before ascending to breathe. In this case, additional activities in which green turtles could be engaged include intraspecific interactions and feeding on sea grass which grows in shallow coastal waters. The way these animals move while feeding is relevant for correct determination of their activity using our devices. Many hours of underwater observation of foraging adult green turtles in Hawaii (Keuper-Bennett pers. comm.) suggest that when individuals feed they generally lie down among the sea grass to graze. When no more food is within easy reach they crawl or move (more by gliding than swimming) to a nearby site. It was possible to show that there are bouts of U-dives where individual dives are very similar to each other in the time/depth diagram, but where the turtle was sometimes active and sometimes motionless during the bottom time (Fig. 3).

a
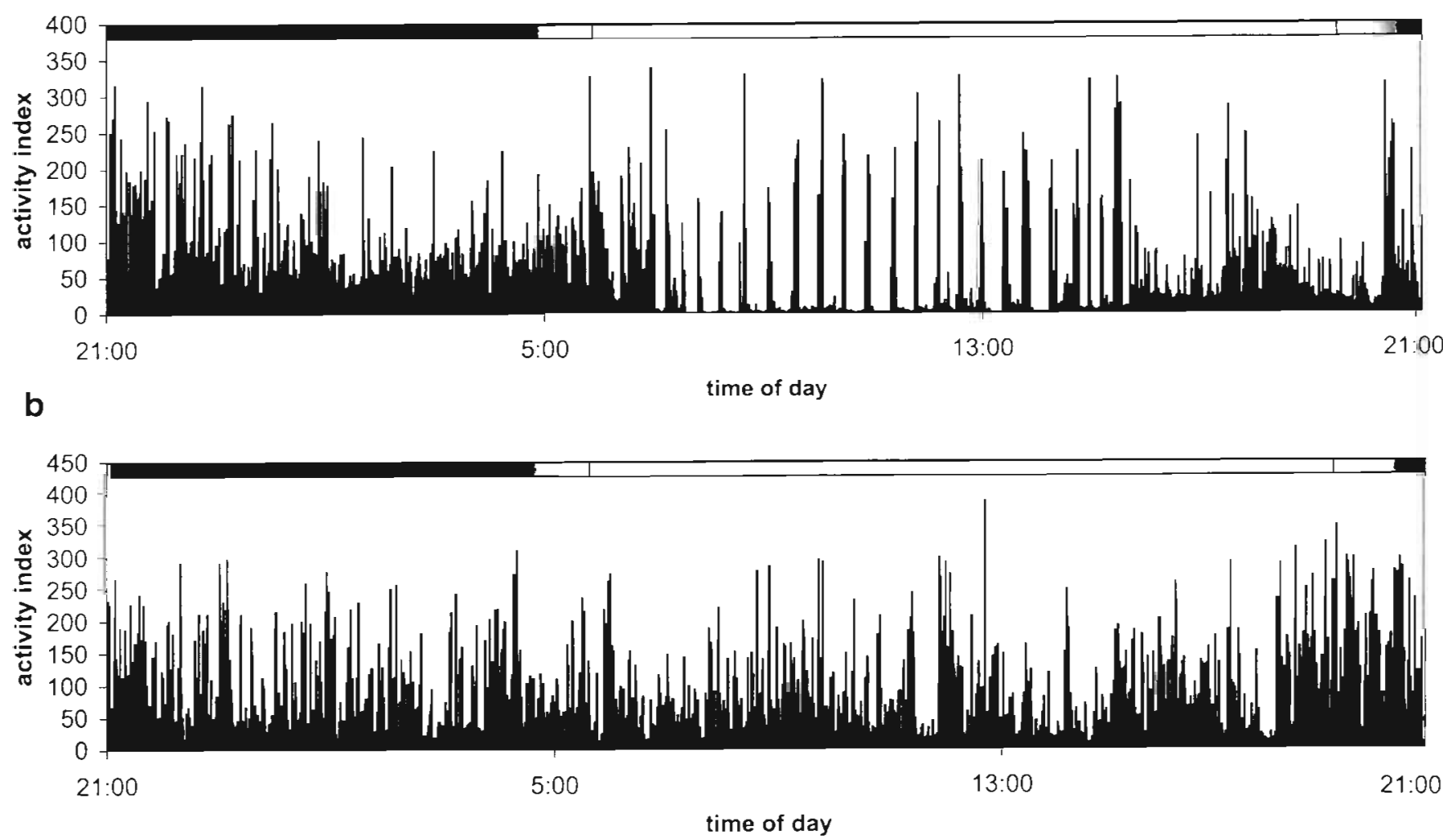

Fig. 7. Two days extracted from Fig. 6 to show the activity of Turtle 2 during a $24 \mathrm{~h}$ period (a) at the beginning of the INP (Day 2) and (b) in the middle of the INP (Day 5). Peaks are due to surfacing events 
Given the fact that there are extensive sea grass beds around northern Cyprus (Zostera marina and Cydomocea nodosa down to $10 \mathrm{~m}$ depth, Posidonia oceanica down to $40 \mathrm{~m}$. Halophila stipulacea in shallow waters; Riedl 1983) and that more than 30 green turtles, including 4 adults (2 gravid females and 2 males), subject to necropsy between 1992 and 1998 have had guts full of freshly ingested sea grass (Godley \& Broderick unpubl. data) leads us to conclude that green turtles nesting in Cyprus feed during the nesting season. A closer look at the percent time spent motionless during the bottom phases of U-dives reveals 3 different categories. The first category of U-dives were true resting dives, where the turtles spend between 80 and $100 \%$ of the bottom time resting (25\% of all U-dives). Secondly, in about $44 \%$ of U-dives, turtles are partly resting and partly moving. This may correspond to a green turtle lying and grazing in the sea grass, only moving from time to time to a better feeding place. Finally, $30 \%$ of the U-dives may contribute to ground surveys and more active foraging behaviour, probably interrupted by interaction with other animals. Based on our findings we suggest 3 main bottom activities: (1) resting, (2) grazing including short distance movements from one patch of food to another and (3) foraging in connection with slow movements along the sea bed to survey the substratum and search for food or resting places.

From a more physiological point of view it is worth mentioning that, although the U-dives were generally the longest, the turtles studied may dive for even longer periods. The correlation between maximum dive depth and total dive duration (Fig. 2) shows that no plateau was reached with regard to time spent underwater as a function of depth which would indicate that the turtles were not exceeding their aerobic dive limit (ADL, Kooyman 1989).

\section{S-dives}

S-dives have not been described for sea turtles in former studies, but have been observed in the yellowbellied sea snake Pelamis platurus (Rubinoff et al. 1986, Graham et al. 1987). However, this dive type has never been observed in the extensive literature on diving mammals and birds and seems to be reptilianspecific. In agreement with the findings of Graham et al. (1987), it was shown that the ascent rate during the dive stop was significantly different from ascent rates in the other phases, thus highlighting the importance of Phase III. Graham et al. (1987) suggested this to be a way of passive locomotion due to the positive buoyancy of the expanding lung. Jacobs (1940) reported that sea turtles inhale a specific limited depth-related amount of air so as to regulate buoyancy during a dive, dependent on the proposed maximum dive depth. By the same token these turtles could take a specific lung volume down to a depth of neutral buoyancy and then drift upwards by gradually gaining positive buoyancy. This mechanism could be further improved as a way of locomotion if the turtle were to execute a flipper beat in a horizontal direction. Indeed, the bounce ascent before the dive stop and the characteristic correlation between the maximum dive depth and the depth of the dive stop would fit in with this picture. This diving behaviour might therefore be interpreted as a way of energy-saving swimming. Weihs (1973), in his modelling study about 'mechanically efficient swimming techniques for fish with negative buoyancy', suggested that such a fish would need less energy for travelling distances when passively sinking down to a certain depth and then actively swimming back to the surface than to swim the distance directly. In this way the fish could make use of their particular state of buoyancy. This is equally known for other diving animals under the expression 'burst and glide' (Weihs 1974, Blake 1983, Kooyman 1989, Spanier et al. 1991). Theoretically, it should not make any difference if energy is saved either via downward gliding caused by negative buoyancy or via upward drifting caused by positive buoyancy. Thus, even if there is no bounce ascent and the dive stop starts right at the point of maximum dive depth, this swimming technique could be used by the turtle. Consequently, we suggest that any dive that shows a well-developed dive stop has the potential for energy saving during travelling dives (Fig. 1b).

\section{V-dives}

Finally, the small number of $\mathrm{V}$-dives indicates that this particular dive type plays a much less important role in green turtle diving behaviour than it does for diving birds and mammals (northern elephant seal Mirounga angustirostris, Le Boeuf et al. 1988; Gentoo penguin Pygoscelis papua, Wilson et al. 1996; Magellanic penguin Spheniscus magellanicus, Peters et al. 1998). V-dives occurred very occasionally between other dives types and may contribute to short underwater surveys or to the orientation of the turtle. It is striking that the V-dives, with very few exceptions, were usually between 3 and $6 \mathrm{~m}$ deep, which shows that green turtles tended not to dive into the deeper part of their depth range without spending a certain amount of time at depth. This can be further explained by the fact that green turtles do not need to scan the water column for prospective prey as, for example, penguins do (Wilson et al. 1996). 


\section{Other dives}

Of all dives $6 \%$ were very difficult to characterise and this could be particularly due to the length of the sampling interval. Wilson et al. (1995) stated that apparent dive profiles may be artefacts arising from measurement intervals that are too long. For example, a diving animal may alter depths or even come to the surface and dive again between 2 measurements without this behaviour being recorded. As a consequence. the resulting profiles would blur the actual dive route taken by the animal and make it difficult to interpret the function of a dive profile. To overcome this problem, Wilson et al. (1.995) suggested setting sampling intervals to be $10 \%$, or less, of the dive duration. In the case of our investigated green turtles dive duration was usually longer than $2.5 \mathrm{~min}$. $(85.3 \%$ of all 'real dives') so that a 15 s interval would give a reliable picture of the performed dive profiles. However, to further elucidate green turtle diving behaviour, shorter sample intervals are needed to resolve short and shallow dives (e.g. SSD).

\section{Daily activity patterns}

The closer examination of the different dive profiles of the green turtles in this study clearly revealed a high activity level throughout the whole inter-nesting period. This finding is quite unexpected when compared to similar studies on green turtle inter-nesting behaviour of geographically different breeding populations. For example Liew \& Chan (1992) reported that green turtles nesting on Pulau Redang, Malaysia, spent the majority of their inter-nesting period resting on the sea floor. The same is true for green turtles nesting on Ascension Island, South Atlantic (Carr et al. 1974, Mortimer \& Portier 1989). Eckert et al. (1996) compared the dive behaviour of nesting leatherback turtles at St. Croix, US Virgin Islands, and at Rantau Abang, Malaysia, and found remarkable differences in dive duration and, hence, activity during a dive: these authors hypothesise that the longer bottom times of Malaysian leatherbacks are due to slower swimming or resting on the bottom, which leads to a reduced rate of $\mathrm{O}_{2}$ consumption. Obviously, nesting sea turtles of the same species do not behave uniformly, but show different strategies in relation to the geographical location of the nesting ground and available resources. Cypriot green turtles rest only $12 \%$ of the inter-nesting time spent underwater (Fig. 8). During the rest of the time these turtles are very likely to be engaged in movements mostly involved in travelling and foraging. The overall high activity level can be put down to the widely distributed sea grass beds around Cyprus

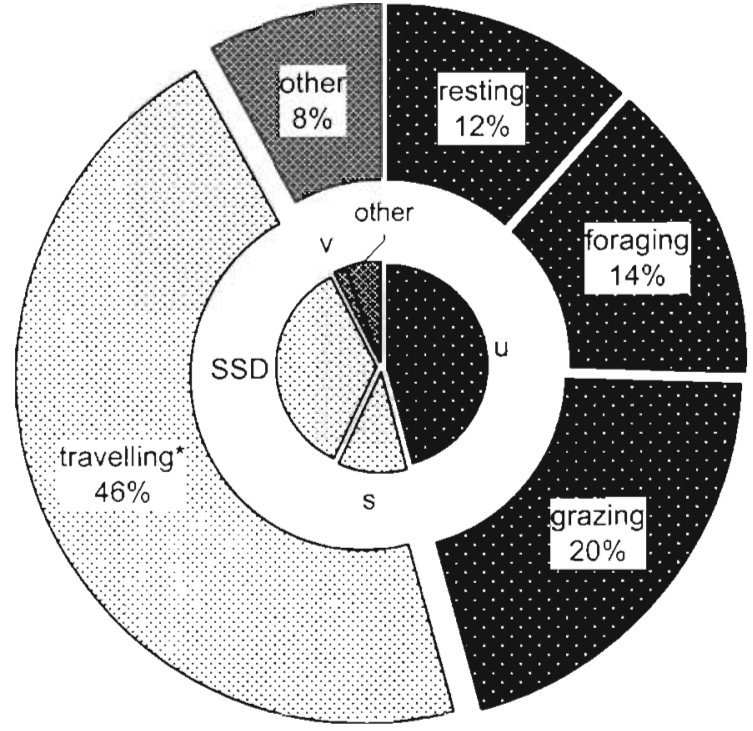

Fig. 8. The Cypriot green turtles were engaged in a variety of activities during the inter-nesting interval which correspond to the proportions of the different dive types. "Includes daily short distance movements within the inter-nesting habitat

whereas it is thought that there is no food available at Ascension Island for the herbivorous green turtle (Bjorndal 1985). Equally, no foraging activities were observed in Malaysian green turtles, whose internesting habitat was described to be sandy with coral or coral-rubble and little algal growth (Liew \& Chan 1992). For this reason green turtles which cannot feed during the nesting season have to rely on energy stores (primarily supplied from fat stores) and thus save energy by resting (Bjorndal 1985). Cypriot green turtles, however, are not confronted with energetic problems due to non-available food resources. These turtles may maintain a high activity level throughout the nesting season and may even spend time travelling along the coastline to select the best inter-nesting sites. Our findings therefore show that green turtles have flexible inter-nesting strategies depending on the resources of the inter-nesting habitat.

\section{CONCLUSIONS}

The use of sophisticated technology helps one to understand the ecology of air-breathing aquatic animals, which are generally difficult to observe in their natural environment. For the first time distinct dive patterns and profiles are presented here in combination with direct activity measurements, which give a clear picture of the inter-nesting activities of green turtles in the Eastern Mediterranean. From these we can learn that green turtles in this region have a diverse 
spectrum of underwater activities contrary to the previously reported extended periods of immobility suggested in other populations.

This knowledge has a certain impact on conservative aspects: it is very important to distinguish between atsea behaviour of different sea turtle populations, because regional conservation plans should be well suited to the specific activities of local populations (e.g. protected areas dependent on turtle home ranges and habitat utilisation, the use of turtle excluder devices [TEDs] by fisheries, and particular protection of sea turtle food resources).

Finally, the particular dive physiology of aquatic reptiles leads to further considerations regarding the diver-surfacer dichotomy. The central difference between divers and surfacers is that divers submerge to achieve a specific task (e.g. prey detection, travelling), then return to the surface, where they live and where body $\mathrm{O}_{2}$ levels are rapidly replenished to 'normal' levels. Surfacers live virtually permanently with depleted $\mathrm{O}_{2}$ body reserves below the surface where almost all activities are performed. 'Normal' activities must be interrupted in order for these animals to move to the surface to quickly rebalance $\mathrm{CO}_{2}$ build-up and $\mathrm{O}_{2}$ depletion. Within the framework of turtles as surfacers it is perhaps useful to reconsider the utility of examining 'dive profiles' as such. Indeed, it might prove more beneficial in this context to look at 'surface profiles'.

Acknowledgements. This study was partly funded by the Institut für Meereskunde, Kiel (travel costs for S.H.). The data loggers were made available by the Deutsche Forschungsgemeinschaft. We would like to acknowledge the field assistance of all the members of the Glasgow University Turtle Conservation Expedition to Northern Cyprus, 1997, and the logistical support of the Society for the Protection of Turtles in Northern Cyprus during fieldwork. A.C.B. would like to acknowledge the assistance of the People's Trust for Endangered Species. We are grateful to Dieter Adelung for his support as well as Jochim Lage and Jens Uwe Voigt for their technical help. Many thanks are due to David Grémillet, Gerrit Peters, Stefan Garthe and Mandy Kierspel for their helpful advice.

\section{LITERATURE CITED}

Bannasch R, Wilson RP, Culik BM (1994) Hydrodynamic aspects of design and attachment of a back-mounted device in penguins. J Exp Biol 194:83-96

Berkson H (1966) Physiological adjustments to prolonged diving in the pacific green turtle (Chelonia mydas agassizii). Comp Biochem Physiol 18:101-119

Bjorndal KA (1985) Nutritional ecology of sea turtles. Copeia $3: 736-751$

Blake RW (1983) Fish locomotion. Cambridge University Press, Cambridge

Broderick AC, Godley BJ (1996) Population and nesting ecology of the green turtle, Chelonia mydas, and the loggerhead turtle, Caretta caretta, in northern Cyprus. Zool Middle East 13:27-46
Butler PJ, Jones DR (1997) Physiology of diving of birds and mammals. Physiol Rev 77:837-899

Carr A, Ross P, Carr S (1974) Internesting behavior of the green turtle, Chelonia mydas, at a mid-ocean island breeding ground. Copeia 3:703-706

Chappell MA, Shoemaker VH, Janes DN, Bucher TL, Maloney SK (1993) Diving behaviour during foraging in breeding Adélie penguins. Ecology 74(4):1204-1215

Eckert SA, Nellis DW, Eckert KL, Kooyman GL (1986) Diving patterns of two leatherback sea turtles (Dermochelys corjacea) during internesting intervals at Sandy Point, St. Croix, U.S. Virgin Islands. Herpetologica 42(3):381-388

Eckert SA, Eckert KL, Ponganis P, Kooyman GL (1989) Diving and foraging behavior of leatherback sea turtles (Dermochelys coriacea). Can J Zool 67:2834-2840

Eckert SA, Liew HC, Eckert KL, Chan EH (1996) Shallow water diving by leatherback turtles in the South China Sea. Chelonian Conserv Biol 2(2):237-243

Graham JB, Gee JH, Motta J, Rubinoff I (1987) Subsurface buoyancy regulation by the sea snake Pelamis platurus. Physiol Zool 60(2):251-261

Grémillet D, Wilson RP, Storch S, Gary Y (1999) Three-dimensional space utilization by a marine predator. Mar Ecol Prog Ser 183:263-273

Hendrickson JR (1980) The ecological strategies of sea turtles. Am Zool 20:597-608

Hochscheid S, Wilson RP (1999) A new method for the determination of at-sea activity in sea turtles. Mar Ecol Prog Ser 185:293-296

Jacobs W (1940) Die Lunge der Seeschildkröte Caretta caretta (L.) als Schwebeorgan. Z Vgl Physiol 27:1-28

Kooyman GL (1989) Diverse divers - physiology and behavior. Springer Verlag, Heidelberg

Kramer DL (1988) The behavioural ecology of air breathing by aquatic animals. Can J Zool 66:89-94

Le Boeuf BJ, Costa DP, Huntley AC, Feldkamp SD (1988) Continuous, deep diving in female northern elephant seals, Mirounga angustirostris. Can J Zool 66:446-458

Liew HC, Chan EH (1992) Biotelemetry of green turtles (CheIonia mydas) in Pulau Redang, Malaysia, during the internesting period. In: Mancini P, Fioretti S, Cristalli $C$, Bedini R (eds) Proceedings of the 12th Biotelemetry Conference, Aug 31-Sep 5. Editric Universitaria Litografia Felia, Ancona, p 157-163

Lutz PL, Musick JA (eds) (1997) The biology of sea turtles. CRC Press, Boca Raton

Mendonca MT, Pritchard PCH (1986) Offshore movements of post-nesting Kemp's ridley sea turtles (Lepidochelys kempi). Herpetologica 42:373-381

Mortimer JA, Portier KM (1989) Reproductive homing and internesting behavior of the green turtle (Chelonia mydas) at Ascension Island, South Atlantic Ocean. Copeid 4: 962-977

Naito Y, Sakamkoto W, Uchida I, Kureha K, Ebisawa T (1990) Estimation of migration route of the loggerhead turtle Caretta caretta around the nesting ground. Nippon Suisan Gakkaishi 56:255-262

Peters G, Wilson RP, Scolaro JA, Laurenti S, Upton J, Galleli H (1998) The diving behaviour of the magellanic penguin (Spheniscus magellanicus) at Punta Norte, Peninsula Valdés, Argentina. Colon Waterbirds 21:1-10

Rice MR, Balazs GH, Hallacher L, Dudley W, Watson G, Krusell K, Larson B (in press) Diving, basking and foraging patterns of a sub-adult green turtie at Punalu'u, Hawaii. In: Proceedings of the 18th Annual Symposium on Sea Turtle Biology and Conservation, March 1998. Mazatlán, Mexico 
Riedl R (1983) Fauna und Flora des Mittelmeeres. Paul Parey Verlag, Hamburg

Rubinoff I, Graham JB, Motta J (1986) Diving of the sea snake Pelamis platurus in the Gulf of Panamá, I. Dive depth and duration. Mar Biol 91:181-191

Sakamoto W. Naito Y, Uchida I, Kureha K (1990) Circadian rhythm on diving motion of the loggerhead turtle Caretta caretta during inter-nesting and its fluctuations induced by the oceanic environmental events. Nippon Suisan Gakkaishi 56(2):263-272

Spanier E, Weihs D, Almong-Shtayer G (1991) Swimming of the Mediterranean slipper lobster. J Exp Mar Biol Ecol 145:15-31

Storch S, Hillis-Starr ZM, Wilson RP (in press) Turtles in the reef: a closer look at the activities of hawksbill turtles in a Caribbean internesting habitat. In: Proceedings of the 19th Annual Symposium on Sea Turtle Biology and Con-

Editorial responsibility: Otto Kinne (Editor),

Oldendorf/Luhe, Germany servation, March 1999, South Padre Island, Texas, USA

Van Dam RP, Diez CE (1996) Diving behavior of immature hawksbills (Eretmochelys imbricata) in a Caribbean cliffwall habitat. Mar Biol 127:171-178

Watson KP, Granger RA (1998) Hydrodynamic effect of a satellite transmitter on a juvenile green turtle (Chelonia mydas). J Exp Biol 201(17):2497-2505

Weihs D (1973) Mechanically efficient swimming techniques for fish with negative buoyancy. J Mar Res 31 (3):194-209

Weihs D (1974) Energetic advantages of burst swimming of fish. $J$ Theor Biol 48:215-229

Wilson RP, Pütz K, Jean-Benoit C, Lage J (1995) Artefacts arising from sampling interval in dive depth studies of marine endotherms. Polar Biol 15:575-581

Wilson RP, Culik BM, Peters G, Bannasch R (1996) Diving behaviour of gentoo penguins, Pygoscelis papua; factors keeping dive profiles in shape. Mar Biol 126:153-162

Submitted: January 21, 1999; Accepted: May 12, 1999

Proofs received from author(s): July 30, 1999 